\title{
ERRATUM
}

Agnes B. Baffoe-Bonnie · Jeffrey R. Smith Dietrich A. Stephan · Johanna Schleutker John D. Carpten • Tommi Kainu Elizabeth M. Gillanders • Mika Matikainen Tanya M. Teslovich $\cdot$ Teuvo Tammela $\cdot$ Raman Sood Andrew M. Balshem - Sheehan D. Scarborough Jianfeng Xu • William B. Isaacs $\cdot$ Jeffrey M. Trent Olli-P. Kallioniemi · Joan E. Bailey-Wilson

\section{A major locus for hereditary prostate cancer in Finland: localization by linkage disequilibrium of a haplotype in the HPCX region}

Published online: 22 October 2005

(C) Springer-Verlag 2005

\section{Human Genetics (2005) 117:307-316}

Unfortunately, two asterisks were missing for the authors Agnes B. Baffoe-Bonnie and Jeffrey R. Smith. These asterisks should indicate that these two authors contributed equally to this work as first authors.

The online version of the original article can be found at http:// dx.doi.org/10.1007/s00439-005-1306-Z

A. B. Baffoe-Bonnie · A. M. Balshem · S. D. Scarborough Division of Population Science,

Fox Chase Cancer Center,

333 Cottman Avenue,

Philadelphia, PA 19111, USA

J. E. Bailey-Wilson $(\bowtie) \cdot$ A. B. Baffoe-Bonnie

Inherited Disease Research Branch, National Human Genome

Research Institute, National Institutes of Health,

333 Cassell Drive, Suite 2000,

Baltimore, MD 21224, USA

E-mail: jebw@nhgri.nih.gov

Tel.: + 1-410-5507509

Fax: $+1-410-5507513$

J. R. Smith

Department of Medicine,

VA Tennessee Valley Healthcare System,

Medical Research Service,

Vanderbilt University Medical Center,

535 Light Hall, 2215 Garland Avenue,

Nashville, TN 37232, USA

D. A. Stephan · J. D. Carpten · J. M. Trent Translational Genomics Research Institution (TGEN), 400 North Fifth, Suite 1600,

Phoenix, AZ 85004, USA
J. Schleutker - T. Kainu

Laboratory of Cancer Genetics,

Institute of Medical Technology,

University of Tampere and Tampere University Hospital,

Lenkkeilijänkatu 6, 33014, Tampere, Finland

E. M. Gillanders · R. Sood

National Human Genome Research Institute,

National Institutes of Health, 50 South Drive,

Bldg. 49-50, Bethesda, MD 20892, USA

M. Matikainen · T. Tammela

Department of Urology, Tampere University

Hospital and Medical School,

University of Tampere, Tampere, Finland

J. Xu

Center for Human Genomics,

Wake Forest University School of Medicine,

Medical Center Boulevard,

Winston-Salem, NC 27157, USA

T. M. Teslovich · W. B. Isaacs

Johns Hopkins School of Medicine,

600 North Wolfe Street, Baltimore, MD 21287, USA

O. Kallioniemi

Medical Biotechnology Department,

VTT Technical Research Center of Finland and

University of Turku, Turku, Finland 